\title{
Ischemic bilateral hippocampal dysfunction during transient global amnesia
}

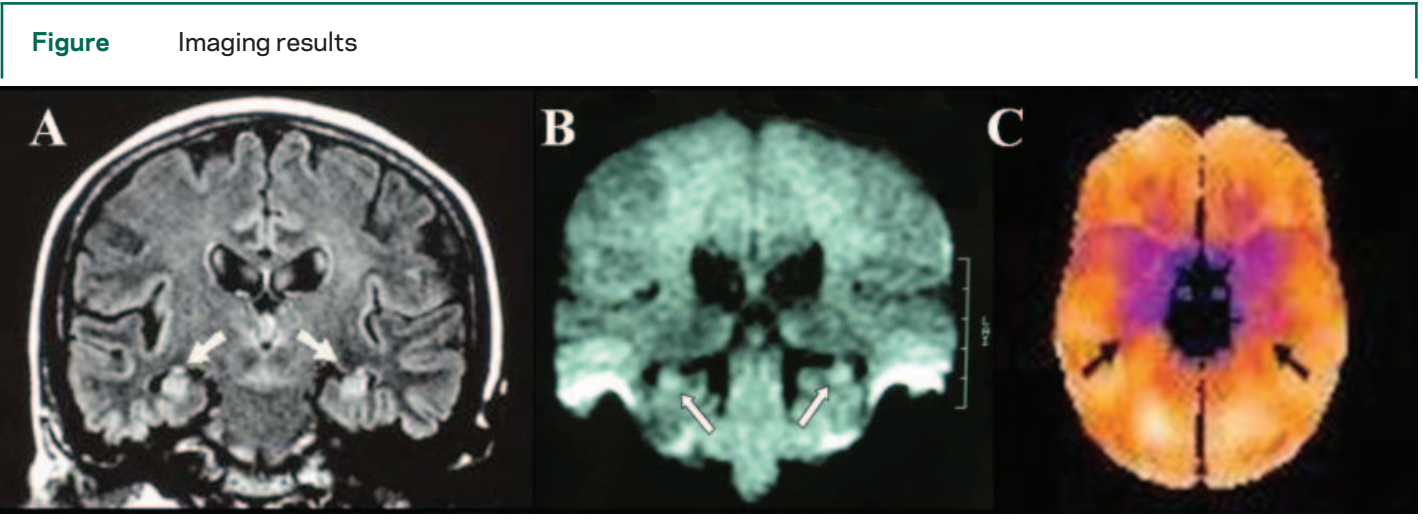

Axial fluid-attenuated inversion recovery (A) and diffusion-weighted (B) MR images obtained 48 hours after the onset of the amnesic syndrome, showing increased signal and diffusion restriction in the hippocampus bilaterally. (C) ${ }^{99 m T c-h e x a m e t h y l-~}$ propyleneamine oxime SPECT images, performed in the same time window, revealing hypoperfusion in the mesial temporal lobes bilaterally.

A 60-year-old woman was referred to our clinic for the sudden onset of anterograde and retrograde amnesia. She was alert and communicative and repeatedly asked the same questions with no changes of consciousness or loss of self-awareness. She had no prior history of migraine, epileptic seizures, head injury, or stroke, and no other neurologic symptoms beside headache were present. The amnesic syndrome resolved spontaneously within 12 hours, with a short, persistent amnesic gap for the main episode. The neuropsychological testing during the amnesic event confirmed the presence of a marked impairment of both anterograde and retrograde episodic memory, with a preservation of personal and conceptual semantic knowledge.

An MR study, with T2 fluid-attenuated inversion recovery (FLAIR) sequences (figure, A, arrows) and diffusion-weighted sequences (figure, B, arrows) performed 48 hours after the onset showed bilateral, high signal, hippocampal lesions. A ${ }^{99 m}$ Tc-hexamethylpropyleneamine oxime SPECT study, performed in the same time window, revealed hypoperfusion in the mesial temporal lobes bilaterally (figure, $\mathrm{C}$, arrows). The patient had no cardiovascular risk factors with the exception of obesity and hyperhomocysteinemia. Moreover, cerebrovascular studies (EKG, transthoracic echocardiography, contrast transcranial and extracranial Doppler sonography) were normal. A follow-up MRI showed that hippocampal lesions were still evident after two months on T2 FLAIR images, whereas they disappeared on diffusion-weighted images. After 1 year transient global amnesia had not recurred and only a brief amnesic gap persisted. The correlation between MR and SPECT images, together with the particular anatomic and vascular architecture of the hippocampus, support the hypothesis that transient global amnesia might be caused by a temporal hypoxicischemic dysfunction in memory-relevant structures induced by hemodynamic factors.

Massimiliano Di Filippo, MD; and Paolo Calabresi, MD, Perugia and Rome, Italy

\section{ACKNOWLEDGMENT}

The authors thank Dr. F. Leone and Dr. P. Chiarini (S.C. Neuroradiologia, Azienda Ospedaliera di Perugia) for the helpful discussion on MR images and Prof. R. Palumbo (Sezione di Medicina Nucleare, Università di Perugia) for the SPECT Images. Disclosure: The authors report no conflicts of interest.

Address correspondence and reprint requests to Dr. M. Di Filippo, Clinica Neurologica, Università di Perugia, Ospedale S. Maria della Misericordia, Via S Andrea delle Fratte, 06156, Perugia, Italy; massimilianodifilippo@virgilio.it 


\section{Neurology}

\section{Ischemic bilateral hippocampal dysfunction during transient global amnesia Massimiliano Di Filippo and Paolo Calabresi Neurology 2007;69;493 \\ DOI 10.1212/01.wnl.0000271085.87627.72}

This information is current as of July 30, 2007

\section{Updated Information \& Services}

Citations

Permissions \& Licensing

Reprints including high resolution figures, can be found at: http://n.neurology.org/content/69/5/493.full

This article has been cited by 3 HighWire-hosted articles: http://n.neurology.org/content/69/5/493.full\#\#otherarticles

Information about reproducing this article in parts (figures,tables) or in its entirety can be found online at: http://www.neurology.org/about/about_the_journal\#permissions

Information about ordering reprints can be found online: http://n.neurology.org/subscribers/advertise

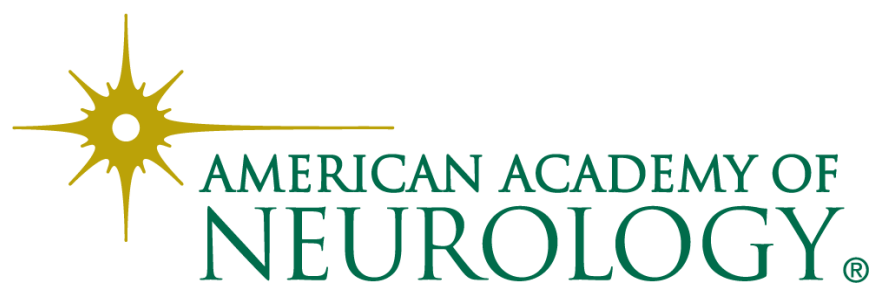

